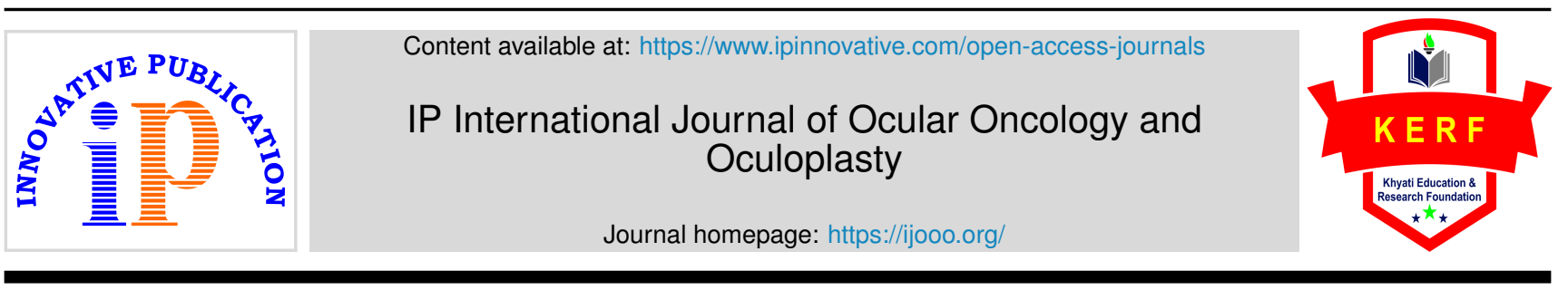

Original Research Article

\title{
Clinical study: Evaluation of the effect of topical nepafenac on central foveal thickness and visual acuity post panretinal photocoagulation in diabetic retinopathy
}

\author{
Vidyashree VA ${ }^{1}$, Ravi B ${ }^{\oplus}$,*, Shashidhar Swamy ${ }^{1}$, Vishwanath B $\mathbf{N}^{\mathbf{1}}$, Swetha Kumari ${ }^{2}$ \\ ${ }^{1}$ Dept. of Ophthalmology, Minto Regional Institute of ophthalmology, Bangalore Medical College and Research Institute, \\ Bengaluru, Karnataka. Fax: India \\ ${ }^{2}$ Dept. of Ophthalmology, Bowring and Lady Curzon Hospital, Bengaluru, Karnataka, India
}

\section{A R T I C L E I N F O}

\section{Article history:}

Received 18-02-2021

Accepted 25-02-2021

Available online 28-04-2021

\section{Keywords:}

Panretinal Photocoagulation

OCT

Central Foveal Thickness

Nepafenac

\begin{abstract}
A B S T R A C T
Objectives: To study the effect of topical nepafenac in patients with diabetic retinopathy following PRP in terms of Central foveal thickness (CFT) and Best corrected visual acuity(BCVA).

Materials and Methods: This is a hospital based randomized control study conducted in Minto ophthalmic hospital, Regional institute of ophthalmology and Bowring and Lady Curzon hospital, from November 2018 to May 2020. Patients with proliferative diabetic retinopathy (PDR) without macular edema were subjected to PRP after detailed clinical evaluation and were divided into test and control groups. All the patients in two groups were matched based on: age, gender, type of diabetes, HBA1C levels and duration of type II diabetes. All patients underwent three sittings of PRP with a gap of one week interval between the sittings. Nepafenac eye drops (Nevanac, Alcon Laboratories Inc, Texas, USA) were used three time a day for a month followed by two time a day for three months in the test group and moxifloxacin eye drops (placebo)(moxicip, Cipla Ltd, India) three time a day for a month followed by two times for 3 months were used in the control group following PRP.

Results: The patients in both test and control group were followed up at 1,2 and 4 months after PRP completion and the changes in CFT and BCVA were recorded. There was increase in CFT on each follow up visit in both test and control group. However increase in CFT in test group was less compared to control group which is statistically significant. $(\mathrm{p}=0.0001)$ There was worsening of BCVA in the test group was less compared to control group which is clinically significant but statisticially insignificant.

Conclusion: Using topical Nepafenac eye drops following PRP for PDR is effective in reducing central foveal thickness and preventing the corresponding worsening of BCVA.

(C) This is an open access article distributed under the terms of the Creative Commons Attribution License (https://creativecommons.org/licenses/by/4.0/) which permits unrestricted use, distribution, and reproduction in any medium, provided the original author and source are credited.
\end{abstract}

\section{Introduction/Background}

Diabetes Melletus is a metabolic disorder characterised by chronic hyperglycemia associated with disturbances in metabolism of carbohydrates, proteins and fats as a result of defect in the secretion of insulin or its action. ${ }^{1}$

India is known as the "diabetic capital of the world". It is estimated that, by 2030 the diabetic population in India will rise to 79.4 million. Diabetic retinopathy is becoming an

\footnotetext{
* Corresponding author.

E-mail address: raviaiims2@gmail.com (Ravi B).
}

important cause of blindness in India. It was $17^{\text {th }}$ cause of blindness 20 years back and now it ascended to $6^{\text {th }}$ position.

Diabetic retinopathy is one of the microvascular complications of DM which affects 1 out of 3 patients with diabetes resulting in poor quality of life in patients with severe DR. ${ }^{2}$ Diabetic retinopathy is the leading cause of blindness among the age group of 25-40 years in the industrialised world. Chronic hyperglycemia is the primary factor responsible for the development of diabetic retinopathy and the other complications of diabetes. The importance of long term glycemic control and the decrease 
in the complications of diabetes is conclusively established by the landmark clinical trials like the Diabetes Control and Complications Trial (DCCT) and the UK prospective Diabetes Study (UKPDS). ${ }^{3,4}$

Proliferative diabetic retinopathy (PDR) is characterized by neovascularization, including neovascularization on disc, neovascularisation elsewhere which leads to vitreous hemorrhage and neovascularisation of iris which may lead to neovascular glaucoma. ${ }^{5}$

Laser photocoagulation is the most common treatment method employed for proliferative diabetic retinopathy. The laser therapy in the form of panretinal photocoagulation where about 2000 large burns each measuring about $500 \mu \mathrm{m}$ of greater intensity are applied on to retina outside the central thirty-degree zones. This tends to decrease the caliber of new vessels and helps in regression of new vessels. ${ }^{6}$

Macular edema is main side-effect of panretinal photocoagulation and may be sufficiently severe to reduce the visual acuity. ${ }^{6}$ Inflammation and altered blood flow are the possible mechanisms responsible for the development of post panretinal photocoagulation macular edema. ${ }^{7}$

Topical treatment with nepafenac (NSAID) is known to produce significant decline in diabetes induced biochemical alterations, including retinal PGE2, CYCLOOXYGENASE 2 , superoxide production. ${ }^{8}$ In addition, cellular and morphological changes such as leucostasis, retinal capillary degeneration, endothelial cell apoptosis were inhibited by Nepafenac. ${ }^{9}$ Our study aims at studying the effect of topical Nepafenac in preventing the development of macular edema following PRP.

\section{Materials and Methods}

Our study was a hospital based randomized control study, conducted from November 2018 to May 2020, at our tertiary eye hospital. A total of 68 eyes of 66 patients with proliferative diabetic retinopathy without preexisting macular edema were included in the study, after taking informed consent. The study was planned and conducted in accordance with the Helsinki Declaration. Institution ethical committee approval was taken. All patients of PDR without macular edema and those requiring PRP were included in the study. Patients with dry eye syndromes, corneal epithelial defect, with prior macular edema, advanced diabetic eye disease, ocular media opacity, prior history of ocular surgery or laser treatment and patients allergic to NSAIDS were excluded from study. Detailed ocular examination included Recording of Visual acuity using Snellen's chart/ LogMAR chart, Examination of the adnexa and extraocular structuresFace, orbits, eyebrows, eyelids, palpebral fissure, extra ocular movements, lacrimal sac, Examination of Anterior segment by slit lamp biomicroscopy, Examination of Posterior segment by ophthalmoscopy (direct and indirect) and +90 D Biomicroscopy. Central foveal thickenss was measured using Spectral domain OCT (Cirrus 5000, Carl Zeiss Meditec, Inc, Dublin, USA) pre and post panretinal photocoagulation of all the patients. Fundus photography and fundus fluroscein angiography were peorformed as and when necessary.

All the patients were divided into two equal groups using random tables

1. Pateints who were given nepafenac eye drops (test

2. Patients who were given carboxymethyl cellulose or moxiflox eye drops(placebo (control

All the patients in two groups were matched based on: age, sex, type of diabetes, HBA1C levels and duration of type II diabetes (defined as the duration from time of diagnosis upto the time of enrolment into the study).

PRPwas done to all the patients in 3 sessions within 3 weeks, with the parameters- retinal spot size $500 \mu \mathrm{m}$, intensity $150-250 \mathrm{mw}$ until a grey white spot seen, duration of $0.1 \mathrm{~s}$, with 1000 spots/eye in the first session, followed by 300-500 spots/eye in the subsequent two sessions. Following which, patients were followed-up at $1^{\text {st }}$ month, $2^{\text {nd }}$ month and $4^{\text {th }}$ month. Efficacy parameters- best corrected visual acuity and central foveal thickness using HD OCT was measured at each visit.

\subsection{Statisitcal analysis}

The data is entered in MS excel and analysed using SPSS Ver 20.0. Descriptive statistics is analysed and represented using mean, median, standard deviation, standard error of mean and categorical variables are represented using percentages. Pearson Chi Square test and Fischer's Exact test is used to measure association between two categorical variables, Independent sample test is used to measure statistically significant difference among two groups.

\section{Observation and Results}

Study was conducted on 66 eyes of 68 patients. There were 19 males $(55.88 \%)$ in test group and 20 males $(58.82 \%)$ in control group. (Table 1) Mean age was 62.20 years in test group and 61.79 years in control group. Mean HBA1c in test group was $8.57 \%$ and in control group was $8.78 \%$ which is statistically insignificant between the groups. 19 patients in test group and 15 patients in control group had systemic hypertension. Mean duration of Diabetes was 15.58years in test group and 15.29years in control group which is comparable. (Table 1) Mean foveal thickness in test group at baseline (Pre PRP), month 1, month 2 and month 4 after PRP was $206.38 \pm 6.38$ microns, $223.79 \pm 9.31$ microns, $227.94 \pm 9.70$ microns and $231.97 \pm 10.06$ microns respectively. Mean foveal thickness in control group at baseline (Pre PRP), month 1, month 2 and month 4 after PRP was 208.79 \pm 7.31 
microns, 228.82 \pm 10.23 microns, 236.52 \pm 12.12 microns and $247.08 \pm 15.78$ microns respectively. There was a significant difference in CFT between test and control group. (Table 2) Mean best corrected visual acuity in test group at baseline (Pre PRP), month 1, month 2 and month 4 after PRP was 0.97.38 $\pm 0.11 \log$ MAR, $1.04 \pm 0.14 \log$ MAR, $1.04 \pm 0.14 \log$ MAR and $1.05 \pm 0.14 \log$ MAR respectively. Mean best corrected visual acuity in control group at baseline (Pre PRP), month 1, month 2 and month 4 after PRP was 0.96.38 $\pm 0.14 \log$ MAR, 1.08 $\pm 0.16 \log$ MAR, $1.09 \pm 0.16 \log$ MAR and $1.13 \pm 0.19 \log$ MAR respectively. There was no statistically difference in BCVA between the groups at any of the follow up. (Table 3) Four eyes (11.76\%) in each group reported blurred vision following PRP. three patients $(8.82 \%)$ in test group and one patient $(2.94 \%)$ in control group reported itching following PRP. One patient $(2.94 \%)$ in each group reported eye pain following PRP. (Table 4)

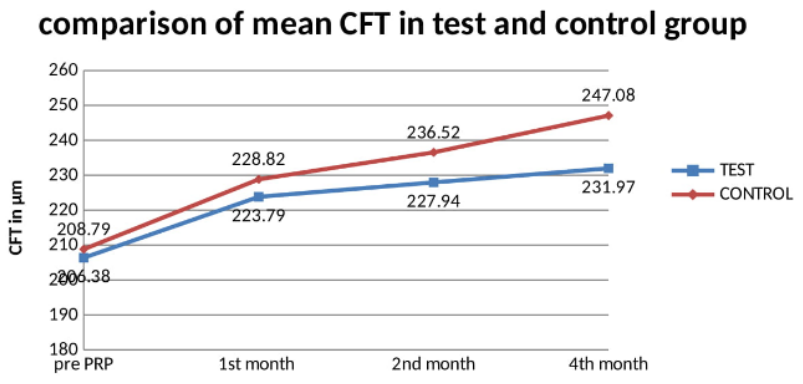

Fig. 1: Line Chart depicting changes in CFT following PRP between test and control group

\section{Discussion}

Diabetes mellitus is one the important etiological factor in causation of preventable blindness. As there is increasing in the prevalence of diabetes, burden of blindness in going to increase. There are various causes for reduction of visual acuity which includes Cataract, Macular edema, tractional retinal detachment, vireous hemorrhage and neovascular glaucoma. PRP is one of the key treatment tool for management of proliferative diabetic retinopathy in developing countries like India. However there are certain complications which occurs with PRP.

In a study conducted by Watanachai $\mathrm{N}$ et al ${ }^{10}$ it was observed that following a single session multispot PRP, there was increase in macular thickness after 1 week of PRP with corresponding mild change in BCVA. Similarly in the study conducted by Mukhthar $\mathrm{A}^{11}$ it was concluded that there is change in central macular thickness and BCVA as measured by OCT following 2 sessions of PRP with PASCAL at the interval of 4 weeks in between the 2 sessions.
Macular edema is main side-effect of panretinal photocoagulation and may be sufficiently severe to reduce the visual acuity. ${ }^{6}$ Inflammation and altered vascular permeability are the possible mechanisms responsible for the development of post panretinal photocoagulation macular edema. ${ }^{7}$

Topical treatment with Nepafenac (NSAID) is known to produce significant decline in diabetes induced biochemical alterations, including retinal PGE2, CYCLOOXYGENASE 2 and superoxide production ${ }^{12}$ In addition, cellular and morphological changes such as leucostasis, retinal capillary degeneration, endothelial cell apoptosis were inhibited by Nepafenac. ${ }^{8}$

A study conducted by David Callanan et al ${ }^{9}$ showed decrease in macular edema as measured by OCT with the use of topical nepafenac twice daily. In our study we have used topical nepafenac to decrease the macular thickness following PRP. The results obtained from our study is similar to the results of the study conducted by Abu Hussein et al. ${ }^{12}$

68 eyes of 66 patients were included in our study, in which 34 eyes were divided into test and control group each. Every patient underwent PRP in 3 sessions at the interval of 1 week, and were followed-up at 1 month, 2 months and 4 months. CFT was more in control group as compared to test group and this change was statisitically significant. Change in BCVA was significant clinically but not statisitically between the groups during follow up.

The changes in central foveal thickness noted during the follow-up in our study and the study conducted by Nahla B. Abu Husseinare are shown in table 6. Similarly the BCVA in our study showed clinically significant changes but was statistically insignificant.

The difference in the BCVA in our study and the study conducted by Nahla B. Abu Husseincan be explained by the observation that the mean age of presentation in our study was 62 years, most of the patients were with the advanced diabetic eye disease and few patients developed cataract during the follow-up. Late presentation due to the lack of proper awareness on the routine screening programmes for diabetic retinopathy was also observed during the study. Non-compliance with medication was also noted in few patients during the follow-up. Comparison of ocular adverse events between our study and the study conducted by Nahla B. Abu Hussein did not show any significant difference.(Table 6)

\section{Conclusion}

Using topical nepafenac eye drops following PRP for proliferative diabetic retinopathy is effective in reducing central foveal thickness and preventing the corresponding worsening of BCVA. 
Table 1: Comparison of other variables between test and control group

\begin{tabular}{|c|c|c|c|c|c|}
\hline \multirow{3}{*}{$\begin{array}{l}\text { Variable } \\
\text { Gender distribution }\end{array}$} & \multicolumn{2}{|c|}{ Test } & \multicolumn{2}{|c|}{ Control } & \multirow[t]{3}{*}{$P$ value } \\
\hline & Males & Females & Males & Females & \\
\hline & 19 & 15 & 20 & 14 & \\
\hline Mean age & \multicolumn{2}{|c|}{62.20 years } & \multicolumn{2}{|c|}{61.79 years } & 0.27 \\
\hline Mean hba1c & \multicolumn{2}{|c|}{$8.57 \%$} & \multicolumn{2}{|c|}{$8.78 \%$} & 0.507 \\
\hline Hypertension & \multicolumn{2}{|c|}{19 patients } & \multicolumn{2}{|c|}{15 patients } & 0.332 \\
\hline Mean duration of diabetes & \multicolumn{2}{|c|}{15.58 years } & \multicolumn{2}{|c|}{15.29 years } & 0.714 \\
\hline
\end{tabular}

Table 2: Comparison of mean central foveal thickness and BCVA between test and control group

\begin{tabular}{lcccc}
\hline & Pre PRP & $\mathbf{1}^{\text {st }}$ month & $\mathbf{2}^{\text {nd }}$ month & $\mathbf{4}^{\text {th }}$ month \\
Test $($ mean \pm SD) & $206.38 \pm 6.38$ & $223.79 \pm 9.31$ & $227.94 \pm 9.70$ & $231.97 \pm 10.06$ \\
Control $($ mean \pm SD) & $208.79 \pm 7.31$ & $228.82 \pm 10.23$ & $236.52 \pm 12.12$ & $247.08 \pm 15.78$ \\
P Value & 0.152 & 0.042 & 0.002 & 0.0001 \\
\hline
\end{tabular}

Table 3: Comparison of mean best corrected visual acuity between test and control group

\begin{tabular}{lcccc}
\hline & Pre PRP & $\mathbf{1}^{\text {st }}$ month & $\mathbf{2}^{\text {nd }}$ month & $\mathbf{4}^{\text {th }}$ month \\
Test $($ mean \pm SD) & $0.97 \pm 0.11$ & $1.04 \pm 0.14$ & $1.04 \pm 0.14$ & $1.05 \pm 0.14$ \\
Control $($ mean \pm SD) & $0.96 \pm 0.14$ & $1.08 \pm 0.16$ & $1.09 \pm 0.16$ & $1.13 \pm 0.19$ \\
P Value & 0.840 & 0.211 & 0.204 & 0.068
\end{tabular}

Table 4: Ocular adverse events during follow-up

\begin{tabular}{lll}
\hline Adverse events & Test & Control \\
Blurred vision & $4(11.76 \%)$ & $4(11.76 \%)$ \\
Itching & $3(8.82 \%)$ & $1(2.94 \%)$ \\
Eye pain & $1(2.94 \%)$ & $1(2.94 \%)$ \\
Eye discharge & $1(2.94 \%)$ & $2(5.88 \%)$ \\
Conjunctivitis & $0(0 \%)$ & $1(2.94 \%)$ \\
Punctate keratitis & $1(2.94 \%)$ & $0(0 \%)$ \\
Chronic redness & $3(8.82 \%)$ & $3(8.82 \%)$ \\
\hline
\end{tabular}

Table 5: Comparison of mean central foveal thickness and BCVA of our study with Nahla B Abu Hussein study

\begin{tabular}{|c|c|c|c|c|c|c|c|c|}
\hline \multirow{2}{*}{$\begin{array}{l}\text { Mean Central foveal } \\
\text { thickness }\end{array}$} & \multicolumn{2}{|c|}{ Pre PRP } & \multicolumn{2}{|c|}{$1^{s t}$ month } & \multicolumn{2}{|c|}{$2^{\text {nd }}$ month } & \multicolumn{2}{|c|}{$4^{t h}$ month } \\
\hline & Test & Control & Test & Control & Test & Control & Test & Control \\
\hline Our study & 206.38 & 208.79 & 223.79 & 228.82 & 227.94 & 236.52 & 231.90 & 247.08 \\
\hline Nahla B. Abu Hussein & 191.63 & 182.68 & 200.44 & 204.18 & 205.56 & 210.25 & 208.22 & 219.68 \\
\hline \multirow[t]{2}{*}{ BCVA } & \multicolumn{2}{|c|}{ Pre PRP } & \multicolumn{2}{|c|}{$\mathbf{1}^{s t}$ month } & \multicolumn{2}{|c|}{$2^{\text {nd }}$ month } & \multicolumn{2}{|c|}{$4^{t h}$ month } \\
\hline & Test & Control & Test & Control & Test & Control & Test & Control \\
\hline Our study & 0.97 & 0.96 & 1.04 & 1.08 & 1.04 & 1.09 & 1.05 & 1.13 \\
\hline Nahla B. Abu Hussein & 0.06 & 0.07 & 0.09 & 0.14 & 0.09 & 0.17 & 0.11 & 0.19 \\
\hline
\end{tabular}

Table 6: Comparison of ocular adverse events between our study and the study conducted by Nahla B. Abu Hussein did not show any significant difference

\begin{tabular}{|c|c|c|c|c|c|c|c|c|c|c|c|c|c|c|}
\hline & \multicolumn{2}{|c|}{$\begin{array}{c}\text { Blurred } \\
\text { Vision }\end{array}$} & \multicolumn{2}{|c|}{ Itching } & \multicolumn{2}{|c|}{ Eye pain } & \multicolumn{2}{|c|}{ Discharge } & \multicolumn{2}{|c|}{ Conjunctivitis } & \multicolumn{2}{|c|}{$\begin{array}{l}\text { Punctate } \\
\text { keratitis }\end{array}$} & \multicolumn{2}{|c|}{$\begin{array}{l}\text { Chronic } \\
\text { redness }\end{array}$} \\
\hline & $\mathrm{T}$ & $\mathrm{C}$ & $\mathrm{T}$ & $\mathrm{C}$ & $\mathrm{T}$ & $\mathrm{C}$ & $\mathrm{T}$ & $\mathrm{C}$ & $\mathrm{T}$ & $\mathrm{C}$ & $\mathrm{T}$ & $\mathrm{C}$ & $\mathrm{T}$ & $\mathrm{C}$ \\
\hline Our study & 4 & 4 & 3 & 1 & 1 & 1 & 1 & 2 & 0 & 1 & 1 & 0 & 3 & 3 \\
\hline $\begin{array}{l}\text { Nahla B Abu } \\
\text { Hussain et al }\end{array}$ & 5 & 3 & 2 & 1 & 1 & 1 & 1 & 2 & 0 & 1 & 0 & 0 & 3 & 3 \\
\hline
\end{tabular}

T: Test C: Control 


\section{Conflicts of Interest}

All contributing authors declare no conflicts of interest.

\section{Source of Funding}

None.

\section{References}

1. Early vitrectomy for severe proliferative diabetic retinopathy in eyes with useful vision: results of a randomized trial-Diabetic Retinopathy Vitrectomy Study report 3. Ophthalmol. 1988;95(10):1307-20.

2. Task Force on Diabetic Eye Care Committee. ICO Guidelines for Diabetic Eye Care. San Francisco, Ca: The International Council of Ophthalmology; 2014.

3. The effect of intensive treatment of diabetes on the development and progression of long-term complications in insulin-dependent diabetes mellitus. N Engl J Med. 1993;329(14):977-86.

4. Intensive blood-glucose control with sulphonylureas or insulin compared with conventional treatment and risk of complications in patients with type 2 diabetes (UKPDS 33). UK Prospective Diabetes Study (UKPDS) Group. Lancet. 1998;352(9131):837-53.

5. Gündüz K, Bakri SJ. Management of proliferative diabetic retinopathy. Compr Ophthalmol Update. 2007;8(5):245-56.

6. Dowler JG. Laser management of diabetic retinopathy. J Royal Soc Med. 2003;96(6):277-9.

7. Singh RP, Staurenghi G, Pollack A, Adewale A, Walker T, Sager $\mathrm{D}$, et al. Efficacy of nepafenac ophthalmic suspension $0.1 \%$ in improving clinical outcomes following cataract surgery in patients with diabetes: an analysis of two randomized studies. Clin Ophthalmol. 2017;11:1021-9. 001:10.2147/opth.s132030.

8. Kern TS, Miller CM, Du Y, Zheng L, Mohr S, Ball SL, et al. Topical Administration of Nepafenac Inhibits Diabetes-Induced Retinal Microvascular Disease and Underlying Abnormalities of Retinal Metabolism and Physiology. Diabetes. 2007;56(2):373-9.

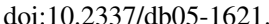

9. Callanan D. Topical nepafenac in the treatment of diabetic macular edema. Clin Ophthalmol. 2008;2(4):689-92. ब01:10.2147/opth.s3965,

10. Watanachai $\mathrm{N}$, Choovuthayakorn J, Patikulsila D, Ittipunkul N. Changes in Central Macular Thickness following Single Session Multispot Panretinal Photocoagulation. J Ophthalmol. 2015:001:1005/2015/522020.

11. Mukhtar A, Khan M, Junejo M, Ishaq M, Akbar B. Treatment of breast ductal carcinoma in situ (DCIS) as a rare entity in an unscreened population in a developing country. Pak J Med Sci. 2016;32(1):221. doi:10.1016/50960-9776(17)30352-1].

12. Hussein NBA, Mohalhal AA, Ghalwash DA, Abdel-Kader AA. Effect of Topical Nepafenac on Central Foveal Thickness following Panretinal Photocoagulation in Diabetic Patients. J Ophthalmol.

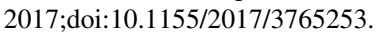

\section{Author biography}

Vidyashree VA, Post Graduate

Ravi B, Assistant Professor (1) https://orcid.org/0000-0002-4550-7441

Shashidhar Swamy, Professor

Vishwanath B N, Associate Professor

Swetha Kumari, Assistant Professor

Cite this article: Vidyashree VA, Ravi B, Swamy S, Vishwanath B N,

Kumari S. Clinical study: Evaluation of the effect of topical nepafenac on central foveal thickness and visual acuity post panretinal photocoagulation in diabetic retinopathy. IP Int J Ocul Oncol Oculoplasty 2021;7(1):77-81. 